\title{
Mapping tree canopies in urban environments using airborne laser scanning (ALS): a Vancouver case study
}

\author{
Giona Matasci ${ }^{1}$, Nicholas C. Coops ${ }^{1 *}$ (D), David A. R. Williams ${ }^{1}$ and Nick Page ${ }^{2}$
}

\begin{abstract}
Background: The distribution of forest vegetation within urban environments is critically important as it influences urban environmental conditions and the energy exchange through the absorption of solar radiation and modulation of evapotranspiration. It also plays an important role filtering urban water systems and reducing storm water runoff.

Methods: We investigate the capacity of ALS data to individually detect, map and characterize large (taller than $15 \mathrm{~m}$ ) trees within the City of Vancouver. Large trees are critical for the function and character of Vancouver's urban forest. We used an object-based approach for individual tree detection and segmentation to determine tree locations (position of the stem), to delineate the shape of the crowns and to categorize the latter either as coniferous or deciduous.

Results: Results indicate a detection rate of $76.6 \%$ for trees $>15 \mathrm{~m}$ with a positioning error of $2.11 \mathrm{~m}$ (stem location). Extracted tree heights possessed a RMSE of $2.60 \mathrm{~m}$ and a bias of $-1.87 \mathrm{~m}$, whereas crown diameter was derived with a RMSE of $3.85 \mathrm{~m}$ and a bias of $-2.06 \mathrm{~m}$. Missed trees are principally a result of undetected treetops occurring in dense, overlapping canopies with more accurate detection and delineation of trees in open areas.

Conclusion: By identifying key structural trees across Vancouver's urban forests, we can better understand their role in providing ecosystem goods and services for city residents.
\end{abstract}

Keywords: Urban forest, Large trees, Light detection and ranging, Airborne laser scanning

\section{Background}

The past decades have seen unprecedented global population growth and urbanization with over $50 \%$ of the Earth's population living within cities (Small 2001; Weng 2014). Canada is at the leading edge of the curve, with $80 \%$ of Canadians now living in cities (Statistics Canada 2017). This places enormous pressures on the planning and management of urban regions to ensure their sustainability, with particular importance on natural urban environments. As a result, a comprehensive understanding of the urban environment is fundamental to ensure sustainable and adaptive urban ecosystems (Williams et al. 2018). The spatial-temporal distribution

\footnotetext{
* Correspondence: nicholas.coops@ubc.ca

${ }^{1}$ Department of Forest Resource Management, University of British Columbia, 2424 Main Mall, Vancouver, BC V6T 1Z4, Canada

Full list of author information is available at the end of the article
}

of vegetation within an urban environment is known as "greenspace", and is a fundamental component of the urban environment. Greenspace has a critical role: it influences urban environmental conditions and energy exchange through the absorption of solar radiation and modulation of evapotranspiration, and plays an important role filtering urban water systems and reducing storm water runoff (Oke 1982; Nowak and Dwyer 2007). Studies have also indicated the significant social (Grahn and Stigsdotter 2003; Westphal 2003), economic (Tyrväinen et al. 2005), and aesthetic values (Tyrväinen et al. 2005; Jim and Chen 2006) associated with urban vegetation (Liu et al. 2017). For example, Kleinman and Geiger (2002) estimated that 100 trees absorb up to 5 tons of $\mathrm{CO}_{2}$ per year from the atmosphere and $450 \mathrm{~kg}$ of pollutants including ozone and particulates. Therefore, within an urban context, greenspaces are the primary means of 
maintaining intact natural ecosystems, capturing and storing carbon, and preserving biodiversity.

Traditionally, information about urban forest canopy has been obtained from field sampling, manual interpretation of aerial photography and, more recently, using technologies such as Google Street View (Liu et al. 2017; Li et al. 2015). In addition, many cities utilize inventory systems to collate tree location, species and condition information for street and park trees. However, these methods are expensive, labor-intensive, and time-consuming, and a lack of complete coverage (Alonzo et al. 2014). Remote sensing offers a unique and efficient approach for understanding and mapping urban landscapes providing synoptic views over large areas. Inclusion of remote sensing data provides spatial layers upon which relationships can be developed between urban greenspace and social issues such as access to parks and recreation areas and provides a platform for extrapolation and expanded assessment into broader contexts nationally and internationally (Sutton and Costanza 2002).

Classification of urban imagery at various spatial resolutions has been a major theme in urban landscape studies (i.e., Schneider 2012; Frolking et al. 2013; Castrence et al. 2014; Lin et al. 2014; Chen et al. 2015; Williams et al. 2018). Previous studies have applied fine spatial resolution imagery (e.g., Benz et al. 2004), hyperspectral data (e.g. Roberts et al. 1998; Heiden et al. 2007), and aerial photography (e.g., Hodgson et al. 2003) all of which offer a high degree of spatial or spectral detail and allow derivation of urban land cover information which in turn is important for inferring land-use, mapping ecosystem services, or modelling of more complex processes like air quality, hydrology, or carbon stocks and flows. Likewise, land cover and its change over time may also help with urban metabolism and ecological footprint studies (Kellett et al. 2013). With respect to mapping tree cover in urban environments optical data from very high spatial resolution satellites such as those of the Worldview and GeoEye series can provide imagery with a pixel size $<0.5 \mathrm{~m}$ and as a result have markedly increased the potential to map and classify tree species within complex urban environments (Novack et al. 2011; Richardson and Moskal 2014). In addition, new methods such as intelligent image segmentation and object-based classification techniques are also highly applicable for urban remote sensing applications (Myint et al. 2011).

Optical sensor-derived data, such as aerial photography and Landsat satellite imagery, however, are generally poor when characterizing the vertical structure of urban vegetation (Plowright et al. 2016). The dimensions and vertical architecture of trees reflect their productivity, age, overall health and vigor (Schomaker et al. 2007). A large, dense crown is an indicator of optimal tree growth, while less dense crowns can be indicative of poor health and stress (Zarnoch et al. 2004; Plowright et al. 2016). Although some vertical tree metrics can be estimated through indirect relationships with optical bands (Cohen and Spies 1992), additional three-dimensional data on tree condition is critically important.

Airborne laser scanning (ALS), also known as light detection and ranging (LiDAR), offers a means to directly measure the three-dimensional structure of vegetation. An ALS instrument emits pulses of light that are reflected off trees, ground surfaces, and other terrestrial features and can penetrate through gaps in the foliage, enabling ALS to directly measure the vertical aspects of tree crowns and forest canopies (Plowright et al. 2016; Coops et al. 2007). A key benefit of ALS is the capacity to reliably obtain high-precision, three-dimensional measurements of buildings and trees over broad spatial scales which, as a result, has attracted significant interest among urban and natural resource managers (Hudak et al. 2009; Williams et al. 2018). ALS has been shown to be highly accurate for estimating a range of vegetation parameters such as tree height, biomass, stand density, basal area, volume, and Leaf Area Index (LAI) (Liu et al. 2017; Riaño et al. 2004; Hudak et al. 2006; Næsset 2007; Edson and Wing 2011). Kim et al. (2009) and Kim et al. (2011) used intensity values and structure variables including standard deviations (SD) of heights, percentiles, and crown ratios derived from leaf-on and leaf-off data, for tree species differentiation. In urban environments Liu et al. (2017) evaluated the potential of ALS to map 15 common urban tree species using a Random Forest (RF) classifier in the City of Surrey, British Columbia, Canada. Results indicate an overall accuracy of $51.1 \%, 61.0 \%$ and $70.0 \%$ using hyperspectral, ALS and the combined data respectively. The overall accuracy for the two most important and iconic native coniferous species improved markedly from $78 \%$ up to $91 \%$ using the combined data. The results of this research highlight that variables derived from ALS data contributed more to the accurate prediction of species than hyperspectral features (Liu et al. 2017).

Large, mature trees are valued for a number of reasons by city dwellers and managers. Larger, older trees have consistently been shown to store more carbon (Stephenson et al. 2014), and support a diversity of bird taxa. The values are difficult, and in some cases impossible, to replicate with large numbers of smaller trees (Le Roux et al. 2015). This is because large older trees provide critical structural complexity that is beneficial to a variety of bird species, particularly habitat specialists that have co-evolved with mature forests (e.g., cavity nesters) (Lindenmayer and Laurance 2016). Older trees can also benefit surrounding trees by fostering a higher diversity of mycorrhizal fungi, which can facilitate nutrient transfer among trees of different age 
classes and species (Simard and Durall 2004; Twieg et al. 2007). For the general population as well these larger trees provide a range of ecosystem services, with large trees having high cultural and emotional value associated with them (Lindenmayer et al. 2014; Pearce et al. 2015). With large, old trees predicted to decline in urban landscapes (Le Roux et al. 2014) it is increasingly critical to identify, map and characterize (in terms of type, height and size) large trees over the city's land base.

The City of Vancouver, British Columbia, Canada, developed an Urban Forest Strategy in 2014 with a specific target of planting 150,000 new trees by 2020 (City of Vancouver 2014). The plan includes policies and bylaws to protect existing trees, plant trees to increase urban forest canopy, and to manage a healthy, resilient urban forest for future generations of the city. Its goal is to plant 150,000 new trees between 2010 and 2020, and increase the urban forest canopy from $18 \%$ to $22 \%$ by 2050 (City of Vancouver 2014). Key to the strategy is to protect and maintain current trees, especially those which are mature and large. To detect, map and characterize these large trees we develop and apply an object-based approach for individual tree detection and segmentation designed to both determine tree locations (position of the stem) and to delineate the shape of the crowns. We then extract attributes of interest such as tree height and crown diameter. Subsequently, using a series of ALS metrics we examine the capacity of ALS data to predict if crowns are deciduous or coniferous. We compare the predictions with both existing databases of tree locations and new field data collections. In this paper we investigate the capacity of ALS data to individually detect, map and characterize large (taller than $15 \mathrm{~m}$ ) trees within the City of Vancouver, recognising the additional cultural and ecological importance these trees have compared to the overall urban forest canopy.

\section{Study area}

Home to over 600,00 residents, the City of Vancouver, $\mathrm{BC}$ is the third largest city in Canada (Statistics Canada 2017). The city is bounded by the Coast Mountains and Burrard Inlet to the north and the Fraser River to the south, which flows into the Strait of Georgia in the west (Williams et al. 2018). Landuse and landcover includes densely built-up areas, extensive areas of lower-density single-family homes as well as varied greenspaces ranging from small parks less than 0.5 ha, to golf courses and the 405 ha Stanley Park (Vancouver Board of Parks and Recreation 2016). Most of Vancouver's native forest vegetation was removed during early settlement and forest harvesting between 1860 and 1910. Remnant areas of temperate rain forest remain in Stanley Park and other large parks and is dominated by large evergreens: western hemlock (Tsuga heterophylla (Raf.) Sarg.), western red cedar (Thuja plicata Donn ex D.Don), and Douglas-fir (Pseudotsuga menziesii (Mirb.) Franco). Exotic tree species are common as park and street trees with dominant species including maples and cherries (over 50\% of all street trees), but also including ashes, lindens, oaks, magnolias, hornbeams, and beeches.

Recent estimates from ALS data indicate that the City of Vancouver has about 18\% urban forest cover, with about $61 \%$ on public lands (streets and parks), and 39\% on private lands (City of Vancouver 2018). Forest cover measurements indicate a minor decline in overall forest cover from $19 \%$ in 1995 to $18 \%$ in 2015 . Most of the tree loss is associated with urban densification, including the loss of large, mature trees.

\section{Data}

The ALS data used in this study was acquired in February 2013 over the boundaries of the City of Vancouver. The discrete-return dataset was provided in 168 nonoverlapping tiles in LAS format with a point density > 12 points $\mathrm{m}^{-2}$. The vertical and horizontal accuracies are 0.18 and $0.36 \mathrm{~m}$ (95\% confidence interval), respectively. An example of a typical point cloud acquired over an urban area is shown in Fig. 1 and shows a profile of ALS returns.

To validate the tree detection, delineation, characterization and species determination, individual tree data within the city was compiled from three different sources. The first was a geodatabase which provides an extensive inventory of trees located in the public parks of the City of Vancouver. It has been collected by a combination of photo-interpretation and field visits. This dataset was used as a base layer providing the spatial coordinates for 22,211 trees. For a subset of 18,146 of these trees, the tree type (deciduous or coniferous) was specified. No height data is available in this existing database. A second dataset with tree height measurements for large significant trees obtained by laser rangefinder and species identification was available for Stanley Park and Kerrisdale area. To complement these datasets, an additional field campaign was completed in four city parks: Queen Elizabeth Park, Memorial West Park, Musqueam Park and Locarno Park. A Vertex ultrasound hypsometer was used to determine the height of identified crowns and the average of two tape measurements on perpendicular axes constituted the recorded value for crown diameter. The compiled dataset presented a total of 74 trees with height and type information, 51 of which with a crown diameter value.

\section{Methods}

The developed workflow for detecting the large trees in this study is detailed below and consists of three key 


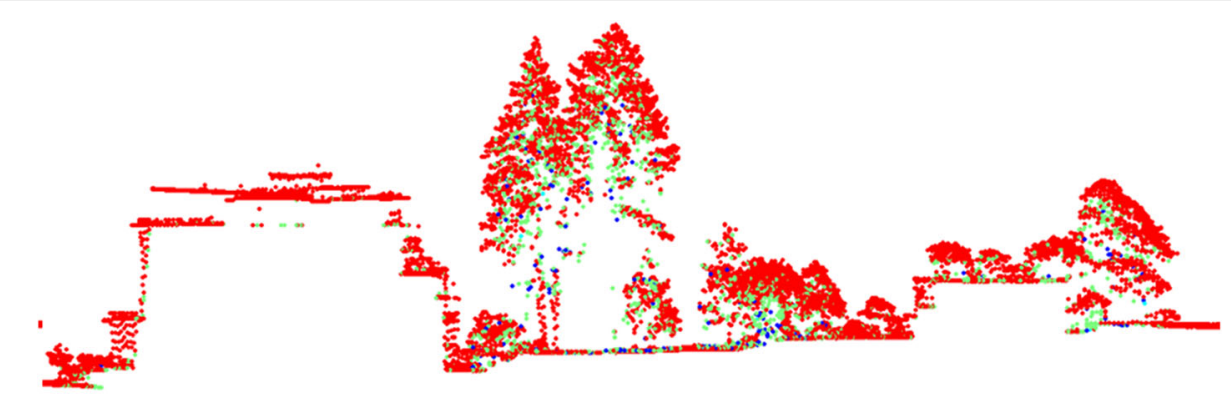

Fig. 1 Example of an ALS point cloud across a small section of the urban environment. Point colored by return type with red corresponding to first returns and other colors second or third returns. Urban structures and ground are typified by a single (first) return whereas vegetation is characterized by a set of multiple return types

steps. First, using the raw point clouds of the LAS files, a canopy height model (CHM) for the study area was derived. Second, a segmentation of the tree crowns took place and tree attributes were extracted. Third, each crown was classified into coniferous/deciduous based on ALS point cloud metrics.

\section{Canopy height model production}

The ALS point clouds were first normalized by extracting the height above the ground of each point. From these normalized point clouds a 0.3-m Digital Surface Model (DSM) was derived providing the height above the ground of each pixel. To do so, the pit-free DSM algorithm (Khosravipour et al. 2016) was used. Finally, a mask was generated to remove buildings and other urban structures as well as low vegetation from the surface resulting in a clean $\mathrm{CHM}$ representing only high vegetation.

\section{Tree crown segmentation and attribute extraction}

For the automatic delineation of tree crowns, the CHM was filtered and smoothed using a moving window applying median and mean filters to attenuate abrupt changes in height. The peaks corresponding to the treetops were then identified as the local maxima of the smoothed surface, with the condition that they were separated by a minimum distance of at least $2.4 \mathrm{~m}(8$ pixels). We then applied a marker-controlled segmentation with the compact watershed algorithm (Soille and Ansoult 1990; Neubert and Protzel 2014) with compactness parameter set to 1 to encourage more regular segments. During this step, the local maxima were used as the markers, i.e., the starting points for the region growing process to delineate each segment. Then, for each crown the height of the treetop (based on the original, unsmoothed $\mathrm{CHM}$ ), the $X$ and $Y$ coordinates of the stem location (as the polygon centroid), and the crown diameter (as the diameter of a circle of equal area) were extracted. As the focus of the paper is on the characterization of big trees, the results were then filtered to include only trees that were higher than $15 \mathrm{~m}$.

\section{Coniferous vs. deciduous classification}

In the final phase, each detected tree was classified as coniferous or deciduous using a Random Forest (RF) classifier (Breiman 2001) based on 27 predictive features derived from a series of ALS metrics (Table 1). Some of the raw ALS metrics were normalized by the 99th percentile of height (closely approximating the height of the tree) in order to avoid scale difference in the final features caused by different tree heights (see description).

The ground truth data providing the reference labels "coniferous" or "deciduous" came from the park trees geodatabase. The reference tree found to be the closest to the segment centroid assigned the ground truth label to the segment. In total, the dataset used to train and validate the model included 1809 coniferous and 4183 deciduous trees. A random $70 \% / 30 \%$ training/validation split was adopted, resulting in 4178 trees in the training set and 1814 in the validation set. A RF classifier with 1000 trees was then trained and applied to the data to label each segment in the area of interest.

\section{Assessment protocol for tree detection and attribute extraction}

The first step in assessing the accuracy of the tree delineation and associated extracted attributes consisted of linking each segmented crown to a given reference tree. To do so, the reference trees were subset to focus on those $>15 \mathrm{~m}$, based on a direct height extraction from the canopy model. If a single reference tree was found within an ALS-derived segment, a direct match was established and the tree was added to the list of matched trees. If more than one reference tree was found inside a single segment, the closest tree to the centroid was considered a match and added to the list. The remaining trees were added to the list of unmatched trees. The 
Table 1 List of the 27 features derived from the ALS metrics extracted for each segment

\begin{tabular}{|c|c|}
\hline Feature name & Description \\
\hline Normalized average height & Average height of all returns above $2 \mathrm{~m}$, normalized by the 99 th percentile of height. \\
\hline Normalized standard deviation of height & $\begin{array}{l}\text { Standard deviation of height of all returns above } 2 \mathrm{~m} \text {, normalized by the 99th percentile } \\
\text { of height. }\end{array}$ \\
\hline Normalized average square height & $\begin{array}{l}\text { Average of the square of the height of all returns above } 2 \mathrm{~m} \text {, normalized by the 99th } \\
\text { percentile of height. }\end{array}$ \\
\hline Skewness of height & Skewness of the height of all returns above $2 \mathrm{~m}$. \\
\hline Kurtosis of height & Kurtosis of the height of all returns above $2 \mathrm{~m}$. \\
\hline Canopy cover from first returns & $\begin{array}{l}\text { Fraction of first returns above the } 2 \mathrm{~m} \text { threshold (number of first returns above } 2 \mathrm{~m} \text { divided } \\
\text { by the total number of first returns) }\end{array}$ \\
\hline Canopy cover from all returns & $\begin{array}{l}\text { Fraction of all returns above the } 2 \mathrm{~m} \text { threshold (number of all returns above } 2 \mathrm{~m} \text { divided by } \\
\text { the total number of all returns) }\end{array}$ \\
\hline $\begin{array}{l}\text { Normalized percentiles of height: } p=10,20,30 \text {, } \\
40,50,60,70,80,90,95\end{array}$ & $\begin{array}{l}\text { Percentiles of height (height below which } p \% \text { of points lay), normalized by the 99th } \\
\text { percentile of height. }\end{array}$ \\
\hline $\begin{array}{l}\text { Bicentiles of height: } b=10,20,30,40,50,60,70 \text {, } \\
80,90,95\end{array}$ & Percentage of the points whose height is below $b \%$ of the 99th percentile of height. \\
\hline
\end{tabular}

reference trees that were found to be outside any segment were also appended to this list.

The list of matched trees is considered to contain the True Positives (TP), i.e., the correctly detected trees, whereas the list of unmatched trees is considered to contain the False Negatives (FN), i.e., the missed reference trees. The TP rate is then computed as TP / (TP + FN). The reference dataset being a presence-only dataset (not an exhaustive list of all tree locations), it was not possible to compute a False Positives rate, i.e., the number of trees incorrectly detected by the algorithm at locations where no trees are present. For the TP, the average horizontal distance (in meters) between reference tree and the matched tree was computed. Additionally, the treetop height and/or crown diameter, if measured in the field, were compared to the ALS estimates and Root Mean Square Error (RMSE) and bias (both in meters) were computed. The accuracy of the coniferous/deciduous classification was assessed based on the independent validation set, with measures such as Overall Accuracy (OA) and F1-scores (harmonic mean of user's and producer's accuracy) derived from the confusion matrix.

\section{Results}

The tree delineation procedure had a TP rate of $76.6 \%$ for trees $>15 \mathrm{~m}(n=5710)$. Examining the 4375 correctly detected trees, the average positioning error of the stem location was $2.11 \mathrm{~m}$. Based on the 68 correctly detected trees having coinciding reference height measurements, the RMSE and bias were equal to $2.60 \mathrm{~m}$ and $-1.87 \mathrm{~m}$, respectively. Crown diameter was estimated with a RMSE of $3.85 \mathrm{~m}$ and a bias of $-2.06 \mathrm{~m}$ using the crown diameter measurements of 45 correctly detected reference trees.
The confusion matrix for the coniferous/deciduous classification is reported in Table 2. The OA was $86.9 \%$, with F1-scores of 0.79 and 0.91 for the coniferous and deciduous classes, respectively. A subset of the developed spatial coverage of large trees $(<15 \mathrm{~m})$ across the city is shown in Fig. 2.

The results indicate the fully automated tree detection and crown delineation approach performs well. The TP rate is consistent with other studies, especially if taking into account that the reference trees were principally located in parks and therefore were often located in high density clusters. The missed trees account for less than $25 \%$ of the reference trees and are principally a result of undetected treetops occurring in dense canopies. Detection and delineation of trees in open areas was in general more accurate. The tree height RMSE and the associated bias suggests the workflow underestimates the height of tall trees, which is a typical of ALS -based estimates of height, as the laser return is unlikely to intersect with the exact apex of the tree. However, field measurement error is also likely, given difficulties in measuring the height of tall trees in the field (all the trees that were measured are $>30 \mathrm{~m}$ ).

Across the City of Vancouver clear differences in the number and height of large trees is apparent (Fig. 3). The urban forest of Stanley Park on the peninsula adjacent to downtown has a number of large mature trees which are dominant in terms of the number, height and

Table 2 Confusion matrix for the coniferous/deciduous classification of the delineated segments

\begin{tabular}{lll}
\hline & Predicted & \\
\hline Actual & Deciduous & Coniferous \\
Deciduous & 1137 & 111 \\
Coniferous & 127 & 439 \\
\hline
\end{tabular}




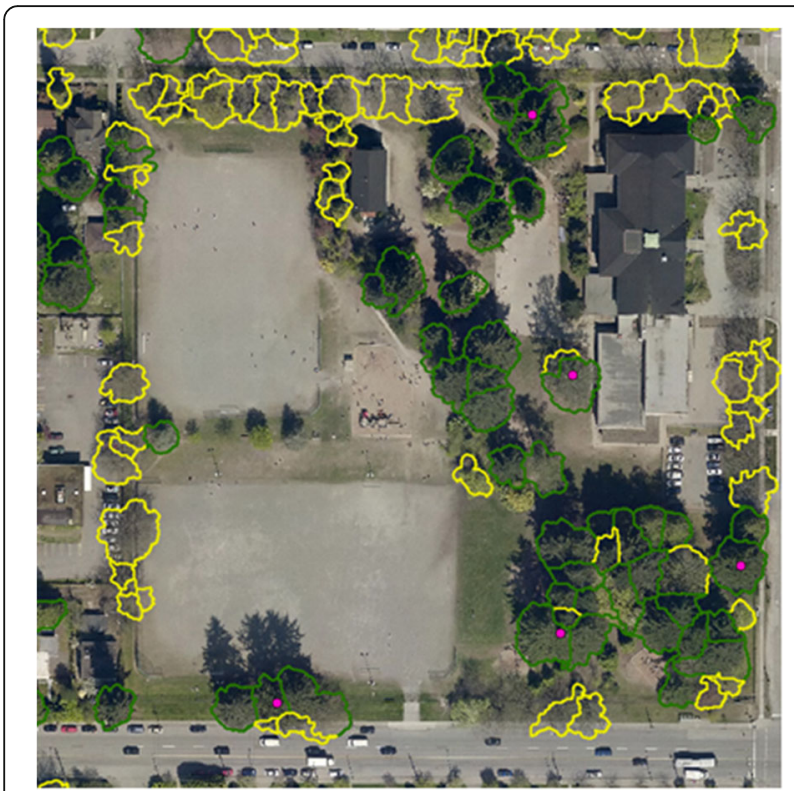

Fig. 2 Detail of the tree crown map (coniferous in green, deciduous in yellow) in a subset of the City of Vancouver with an orthophoto as a background and the 5 reference trees located in the area (pink dots)

crown size. Generally however there is an East - West gradient with postal codes west in the city generally being dominated by taller, coniferous trees, whereas in the east the tree height is lower and stands have generally dominated by deciduous trees. The only exception to this is Killarney in the south east which has values dominated by the mature forest in the Fraserview Golf Course.

Figure 4 shows summaries of the distribution of average tree height $(>15 \mathrm{~m})$, density of tall trees per ha, average crown diameter and percentage of conifer by postcode across the city. The results mirror those in Fig. 3 with an increase in the density and height of

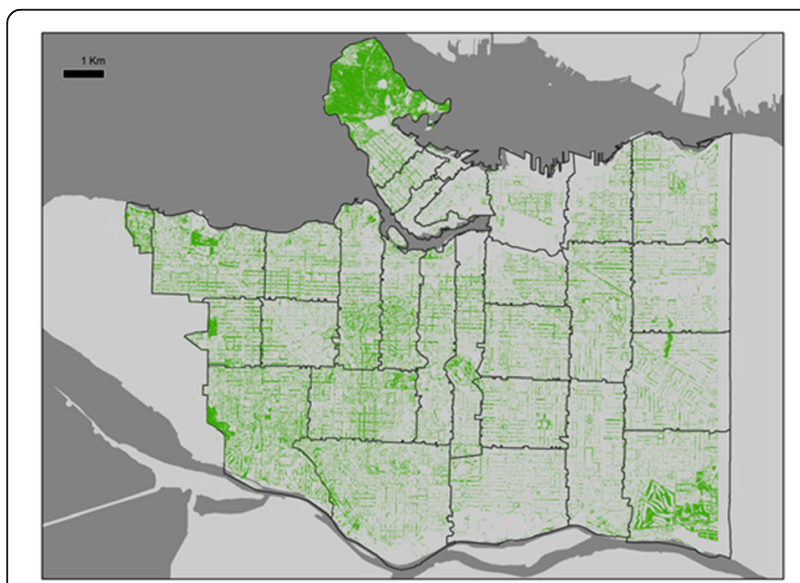

Fig. 3 Mapped locations of all detected trees $>15 \mathrm{~m}$ across the City of Vancouver trees from east to west (with the exception of the Fraserview Golf Course). Tall trees are more associated with conifer compared to deciduous tree species with larger conifers such as western hemlock, western red cedar, and Douglas-fir dominating on the western side of the city.

\section{Discussion}

Results presented in the case study demonstrate that individual large tree canopies can be mapped from ALS point clouds-derived rasters and with an object-based workflow. The use of the high-density ALS data also proved potential in the fully-automatic classification of trees as either coniferous or deciduous. While the deciduous/coniferous tree classification was accurate in this study, the tree crown attributes for deciduous trees are likely to present errors due to the lack of a complete vegetated crown at the time of ALS acquisition in February. Crown diameter was also underestimated (on average by $2 \mathrm{~m}$ ) mainly due to overlapping crowns in dense canopies. In open areas, isolated trees were well delineated. Part of the height and crown diameter mismatch may be attributed to the four year lag between the ALS acquisitions (in 2013) and the field data collection (mainly in 2017), an interval during which some of the younger trees have grown.

The ALS data acquired for this study was acquired principally for the purposes of developing high quality digital terrain information across the city. The leaf-off ALS acquisition may have hampered the results in the detection/delineation of deciduous trees, lowering thus the overall TP rate. It is not uncommon that leaf-off collections are undertaken in order to obtain precise DEM's with a focus on urban structures, hydrology and urban water movement. Leaf-off collections can result in sparse point clouds for deciduous stands because of the large number of laser pulses penetrating the canopy. Improved delineation of the crowns for deciduous trees enabled by a leaf-on acquisition may result in the extraction of more meaningful ALS-based features, in turn potentially enhancing the classification results.

With relation to the choice of extracting trees taller than $15 \mathrm{~m}$, a comparison of tree delineation methods by Jakubowski et al. (2013) suggested that ALS data with an average of around 2 points. $\mathrm{m}^{-2}$ was sufficient for detecting large individual trees. In general, attempts to extract individual tree attributes have relied on higher densities. Point densities $>9$ points $\cdot \mathrm{m}^{-2}$ were used to accurately extract tree height, base height, crown diameter, and crown volume as well as perform segmentation of individual trees directly from the raw LiDAR point cloud (Zhang et al. 2015). Smaller trees might require even higher density. In terms of the accuracy assessment, to effectively optimize the parameters of the automatic 

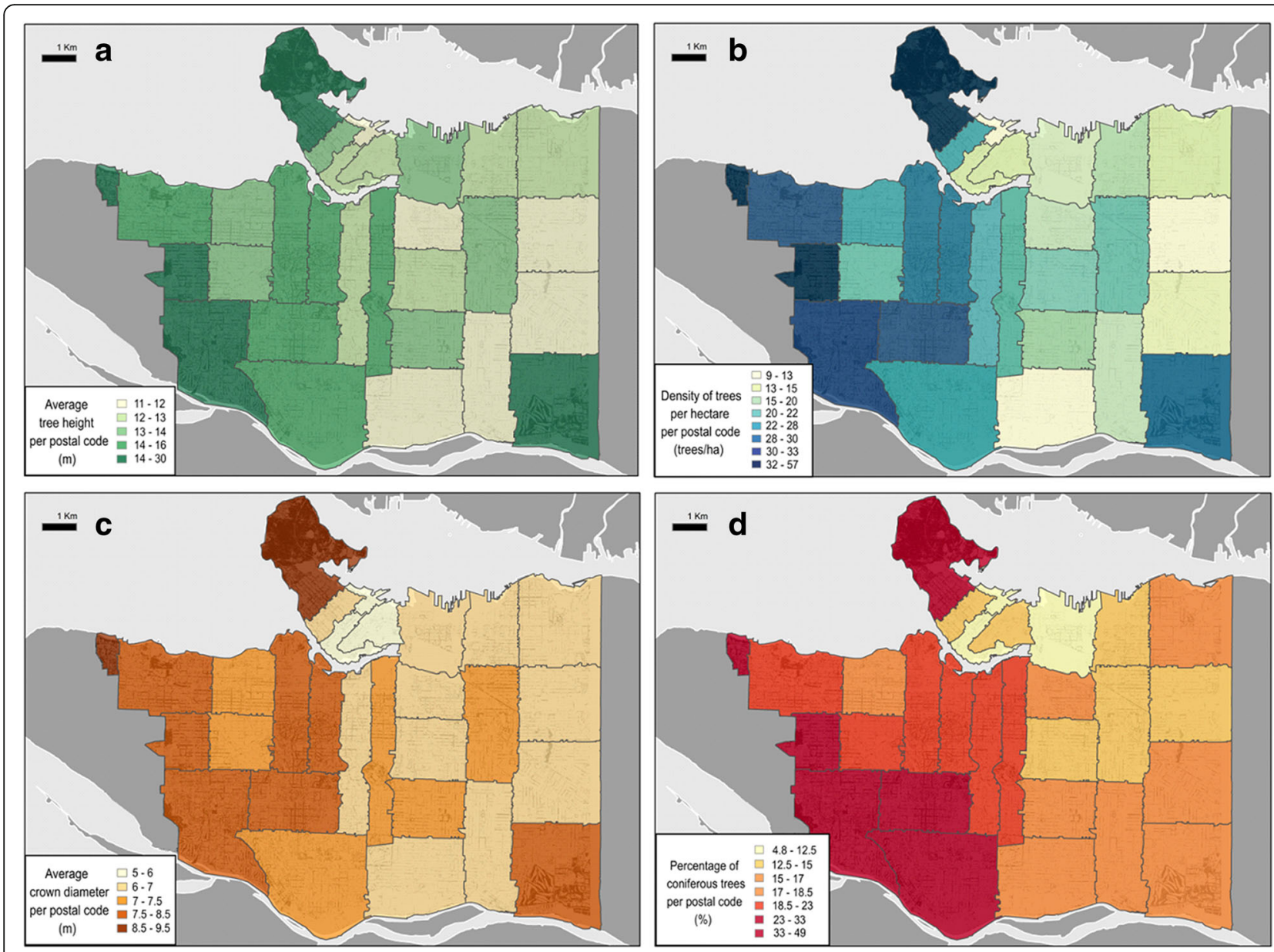

Fig. 4 Summary of detected tree attributes by postcode (a) Height, (b) Density, (c) Crown diameter and (d) \% conifer

workflow, a comprehensive validation dataset is required. In addition future work could focus on the extraction of other tree attributes besides tree location and crown size. For example, individual crown structure can be examined using ALS as filled and open volumes within a canopy (Lefsky et al. 1999). The approach involves superimposing a grid over individual canopies composed of $0.1 \mathrm{~m}^{3}$ voxels up to the level of the highest LiDAR return. These cells are classified as either "filled" or "empty" volume depending on whether a return was recorded within the voxel and as either "euphotic" zone, if the cell is located within the uppermost $65 \%$ of all filled volumes, or as "oligophotic" zone if it is located below this point in the profile. Coops et al. (2007) found that the overall canopy surface structure of Douglas-fir stands in coastal British Columbia, Canada, were characterized by the total amount of the "open gap" canopy volume profile class with dense, shorter stands showing an even upper canopy surface, while the mixed, more variable crown structures, have a significantly higher amount of open gaps, which are indicative of increased total canopy surface.
A small field campaign was conducted for this study to acquire height and crown diameter for a small set of sample trees. However, a complete census of tree locations over a test area may be desirable to assess and compare the delineation assumptions which should rely not only on TP rate but also on the False Positive rate (reporting on false alarms, i.e., segments that do not correspond to any actual tree). Manual crown delineation as done by a photo-interpreter based on an orthophoto could also be useful, even though overlapping crowns may be hard to correctly digitize.

Across the study we demonstrate that although there is variation in the number and size of trees across the city, Vancouver is still very green. This agrees with previous studies which demonstrate that only approximately $22 \%$ of the larger Metro Vancouver is urban land cover (Williams et al. 2018). The City of Vancouver had previously estimated its canopy cover from ALS data to be $18 \%$, comparable to the cities of Victoria, BC (18\%) and Seattle, WA (23\%) (City of Vancouver 2014). However, our results are consistent with Williams et al. (2018) who found that broadleaf and coniferous trees cover 
about $19 \%$ and $6 \%$ of Vancouver's area, respectively, which they found was an increase of $7 \%$ on the previous estimate for a total canopy cover of about $25 \%$. Similarly, Li et al. (2015) and Seiferling et al. (2017) using Google Street view imagery to estimate street-level canopy cover in Vancouver and estimated a median 25.9\% street-level canopy cover for the City.

\section{Conclusion}

We presented a case study relating on an effort to map large trees in the city of Vancouver, BC, Canada. The methodology we detailed herein revolves around an object-based image analysis applied on ALS data to detect tall trees locations and to extract attributes of interest, including tree height, crown diameter and coniferous/deciduous class. By identifying large trees in Vancouver, this study adds to previous information gathered about canopy cover in Vancouver by identifying structural keystones (Le Roux et al. 2015) in Vancouver's urban forests. Because large trees are so valuable due to their form and function, their identification is critical for a comprehensive understanding of the urban forest.

\section{Abbreviations}

ALS: Airborne laser scanning; DSM: Digital Surface Model; FP: False Positives; LiDAR: Light Detection and Ranging; OA: Overall Accuracy; RMSE: Root Mean Square Error; TP: True Positives

\section{Acknowledgements}

We would like to thank Ira Sutherland (https://vancouversbigtrees.com/) for kindly sharing his tall trees datasets and for the insightful discussion on Vancouver's urban forest. Marco Sanelli is thanked for his help with the field data collection and with the map visualizations. We also acknowledge the useful and insightful comments of the two anonymous reviewers and the editorial team.

\section{Availability of data and materials}

LiDAR data for the Vancouver region is available at http://data.vancouver.ca/ datacatalogue/LiDAR2013.htm

\section{Authors' contributions}

All authors conceived the study. GM and DW undertook the image analysis, GM, DW and NC undertook statistical analysis. All authors contributed the writing. All authors read and approved the final manuscript.

\section{Ethics approval and consent to participate}

Not applicable.

\section{Consent for publication}

Not applicable.

\section{Competing interests}

The authors declare that they have no competing interests.

\section{Author details}

'Department of Forest Resource Management, University of British Columbia, 2424 Main Mall, Vancouver, BC V6T 1Z4, Canada. ${ }^{2}$ Vancouver Board of Parks and Recreation, 2099 Beach Avenue, Vancouver, BC V6G 1Z4, Canada.
Received: 13 April 2018 Accepted: 3 July 2018

Published online: 03 August 2018

\section{References}

Alonzo M, Bookhagen B, Roberts DA (2014) Urban tree species mapping using hyperspectral and lidar data fusion. Remote Sens Environ 148:70-83. https:// doi.org/10.1016/j.rse.2014.03.018

Benz UC, Hofmann P, Willhauck G, Lingenfelder I, Heynen M (2004) Multiresolution, object-oriented fuzzy analysis of remote sensing data for GISready information. ISPRS J Photogramm Remote Sens. 58(3-4):239-258. https://doi.org/10.1016/J.ISPRSJPRS.2003.10.002.

Breiman L (2001) Random forests. Machine Learn 45(1):5-32. https://doi.org/10. 1023/A:1010933404324

Castrence M, Nong D, Tran C, Young L, Fox J (2014) Mapping urban transitions using multi-temporal landsat and DMSP-OLS night-time lights imagery of the red river delta in Vietnam. Land 3(1):148-166. https://doi.org/10.3390/ land3010148

Chen SS, Yan Y, Gao Q, Liu D (2015) Quantifying circular urban expansion patterns of compact Chinese cities: the case of Yangtze River Delta, China. Environ Plann B Plann Design 42:279-299. https://doi.org/10.1068/b120004p

City of Vancouver (2014) City of Vancouver Urban Forest Strategy. Vancouver http://vancouver.ca/home-property-development/urban-forest-strategy.aspx. Accessed at 12 Feb 2018.

City of Vancouver and Vancouver Park Board. 2018. Urban Forest Strategy: 2018 Update. Vancouver Canada. 60 pp.

Cohen WB, Spies T (1992) Estimating structural attributes of Douglas-fir/western hemlock forest stands from Landsat and SPOT imagery. Remote Sens Environ 41(1):1-17. https://doi.org/10.1016/0034-4257(92)90056-P

Coops NC, Hilker T, Wulder MA, Stonge B, Newnham G, Siggins A, Trofymow JA (2007) Estimating canopy structure of Douglas-fir forest stands from discretereturn LIDAR. Trees 21(3):295-310

Edson C, Wing MG (2011) Airborne light detection and ranging (LiDAR) for individual tree stem location, height, and biomass measurements. Remote Sens 3(11):2494-2528. https://doi.org/10.3390/rs3112494

Frolking S, Milliman T, Seto KC, Ma F (2013) A global fingerprint of macro-scale changes in urban structure from 1999 to 2009. Environ Res Lett 8(2):24004. https://doi.org/10.1088/1748-9326/8/2/024004

Grahn P, Stigsdotter UA (2003) Landscape planning and stress. Urban Forestry and Urban Greening. 2(1):1-18. https://doi.org/10.1078/1618-8667-00019.

Heiden U, Segl K, Roessner S, Kaufmann H (2007) Determination of robust spectral features for identification of urban surface materials in hyperspectral remote sensing data. Remote Sensing of Environment, 111(4):537-52 https:// doi.org/10.1016/J.RSE.2007.04.008.

Hodgson ME, Jensen JR, Tullis JA, Riordan KD, Archer CM (2003) Synergistic Use of Lidar and Color Aerial Photography for Mapping Urban Parcel Imperviousness. Photogramm Eng Remote Sens. 69(9):973-980. https://doi. org/10.14358/PERS.69.9.973.

Hudak A, Crookston N, Evans J (2006) Regression modeling and mapping of coniferous forest basal area and tree density from discrete-return lidar and multispectral satellite data. Can J For Res 32(2):126-138

Hudak AT, Evans JS, Smith AMS (2009) LiDAR utility for natural resource managers. Remote Sens. https://doi.org/10.3390/rs1040934

Jakubowski MK, Li W, Guo Q, Kelly M (2013) Delineating Individual Trees from Lidar Data: A Comparison of Vector- and Raster-based Segmentation Approaches. Remote Sens. 5, 4163-86.

Jim CY, Chen WY (2006) Impacts of urban environmental elements on residential housing prices in Guangzhou (China). Landscape and Urban Planning, 78(4): 422-434. https://doi.org/10.1016/j.landurbplan.2005.12.003.

Kellett R, Christen A, Coops NC, van der Laan M, Crawford BR, Tooke TR, Olchovski I (2013) A systems approach to carbon cycling and emissions at an urban neighbourhood scale. Landscape Urban Plan 110:43-58

Khosravipour A, Skidmore AK, Isenburg M (2016) Generating spike-free digital surface models using LiDAR raw point clouds: a new approach for forestry applications. Int J Appl Earth Observ Geoinform. https://doi.org/10.1016/j.jag. 2016.06.005

Kim S, Hinckley T, Briggs D (2011) Classifying individual tree genera using stepwise cluster analysis based on height and intensity metrics derived from airborne laser scanner data. Remote Sens Environ 115(12):3329-3342

Kim S, McGaughey R, Andersen H (2009) Tree species differentiation using intensity data derived from leaf-on and leaf-off airborne laser scanner data. Remote Sens Environ 113(8):1575-1586 
Kleinman M, Geiger JR (2002) Trees in our city. Davis, CA: Center for Urban Forest Research, Pacific Southwest Research Station, USDA Forest Service; ppt.13.

Le Roux DS, Ikin K, Lindenmayer DB, Manning AD, Gibbons P (2014) The future of large old trees in urban landscapes. PLoS One 9(6). https://doi.org/10.1371/ journal.pone.0099403

Le Roux DS, Ikin K, Lindenmayer DB, Manning AD, Gibbons P (2015) Single large or several small? Applying biogeographic principles to tree-level conservation and biodiversity offsets. Biol Conserv 191:558-566. https://doi. org/10.1016/j.biocon.2015.08.011

Lefsky MA, Cohen WB, Acker SA, Parker GG, Spies TA, Harding DJ (1999) Lidar remote sensing of the canopy structure and biophysical properties of Douglas-fir western hemlock forests. Remote Sens Environ 70(3):339-361

Li X, Zhang C, Li W, Ricard R, Meng Q, Zhang W (2015) Assessing street-level urban greenery using Google street view and a modified green view index. Urban Forest Urban Green 14(3):675-685. https://doi.org/10.1016/j.ufug.2015.06.006

Lin J, Liu X, Li K, Li X (2014) A maximum entropy method to extract urban land by combining MODIS reflectance, MODIS NDVI, and DMSP-OLS data. Int J Remote Sens 35(18):6708-6727. https://doi.org/10.1080/01431161.2014. 960623

Lindenmayer DB, Laurance WF (2016) The unique challenges of conserving large old trees. Trends in Ecol Evol 31(6):416-418. https://doi.org/10.1016/j.tree. 2016.03.003

Lindenmayer DB, Laurance WF, Franklin JF, Likens GE, Banks SC, Blanchard BW, Gibbons P, Ikin K, Blair D, McBurney L, Manning AD, Stein JAR (2014) New policies for old trees: averting a global crisis in a keystone ecological structure. Conserv Lett 7(1):61-69. https://doi.org/10.1111/conl.12013

Liu L, Coops NC, Aven NW, Pang Y (2017) Mapping urban tree species using integrated airborne hyperspectral and LiDAR remote sensing data. Remote Sens Environ. 200, 170-82.

Myint S, Gober P, Brazel A, (2011) Per-pixel vs. object-based classification of urban land cover extraction using high spatial resolution imagery. Remote Sens. Environ. 115, 1145-61.

Næsset E (2007) Airborne laser scanning as a method in operational forest inventory: status of accuracy assessments accomplished in Scandinavia. Scand J Forest Res 22(5):433-442

Neubert P, Protzel P (2014) Compact watershed and preemptive slic: On improving trade-offs of superpixel segmentation algorithms. International Conference on Pattern Recognition (ICPR). https://www.tu-chemnitz.de/etit/ proaut/publications/cws_pSLIC_ICPR.pdf. Accessed at 12 Feb, 2018

Novack T, Esch T, Kux H, Stilla U, (2011) Machine learning comparison between WorldView-2 and QuickBird-2-simulated imagery regarding object-based urban land cover classification. Remote Sens. 3, 2263-2282.

Nowak DJ, Dwyer JF (2007) Understanding the benefits and costs of urban forest ecosystems, pp. 25-46. In Urban and Community Forestry in the Northeast. Kuser, J., Ed. New York: Springer Science and Business Media.

Oke TR (1982) The energetic basis of the urban heat island. Quarterly Journal of the Royal Meteorological Society, 108(455):1-24

Pearce LM, Davison A, Kirkpatrick JB (2015) Personal encounters with trees: the lived significance of the private urban forest. Urban For Urban Green 14(1):17. https://doi.org/10.1016/j.ufug.2014.11.003

Plowright AA, Coops NC, Eskelson BNI, Aven NW (2016) Assessing urban tree condition using airborne light detection and ranging Urban Forestry \& Urban Greening 19 p 140-150. https://doi.org/10.1016/j.ufug.2016.06.026.

Riaño D, Valladares F, Condés S, Chuvieco E (2004) Estimation of leaf area index and covered ground from airborne laser scanner (Lidar) in two contrasting forests. Agric For Meteorol 124. https:/doi.org/10.1016/j.agrformet.2004.02.005

Richardson J, Moskal L, (2014) Uncertainty in urban forest canopy assessment: Lessons from Seattle, WA, USA. Urban For. Urban Green. 13:152-57.

Roberts DA, Gardner M, Church R, Ustin S, Scheer G, Green RO (1998) Mapping Chaparral in the Santa Monica Mountains Using Multiple Endmember Spectral Mixture Models. Remote Sens of Environ. 65(3):267-279. https://doi. org/10.1016/S0034-4257(98)00037-6.

Schneider A (2012) Monitoring land cover change in urban and peri-urban areas using dense time stacks of Landsat satellite data and a data mining approach. Remote Sens Environ 124:689-704. https://doi.org/10.1016/j.rse. 2012.06 .006

Schomaker ME, Zarnoch SJ, Bechtold WA, Latelle DJ, Burkman WG, Cox SM (2007) Crown-Condition Classification : A Guide to Data Collection and Analysis. General technical report SRS-102. Ashville North Carolina: United States Department of Agriculture, Forest Service, Southern Research Station
Seiferling I, Naik N, Ratti C, Proul R (2017) Green streets - quantifying and mapping urban trees with street-level imagery and computer vision. Landscape Urban Plan 165:93-101. https://doi.org/10.1016/j.landurbplan.2017.05.010

Simard SW, Durall DM (2004) Mycorrhizal networks: a review of their extent, function, and importance. Can J Bot 82(8):1140-1165. https://doi.org/10.1139/ b04-116

Small C (2001) Estimation of Urban Vegetation Abundance by Spectral Mixture Analysis. Int J Remote Sens Environ 22:1305-34

Soille PJ, Ansoult MM (1990) Automated basin delineation from digital elevation models using mathematical morphology. Signal Process 20(2):171-182

Statistics Canada (2017) Population of census metropolitan areas. http://www. statcan.gc.ca/tables-tableaux/sum-som/l01/cst01/demo05a-eng.htm. Accessed 12 Feb 2018

Stephenson NL, Das AJ, Condit R, Russo SE, Baker PJ, Beckman NG, Coomes DA, Lines ER, Morris WK, Ruger N, Alvarez E, Blundo C, Bunyavejchewin S, Chuyong G, Davies SJ, Duque A, Ewango CN, Flores O, Franklin JF, Grau HR, Hao Z, Harmon ME, Hubbell SP, Kenfack D, Lin Y, Makana J-R, Malizia A, Malizia LR, Pabst RJ, Pongpattananurak N, Su S-H, Sun I-F, Tan S, Thomas D, van Mantgem PJ, Wang X, Wiser SK, Zavala MA (2014) Rate of tree carbon accumulation increases continuously with tree size. Nature 507(7490):90-93. https://doi.org/10.1038/nature12914

Sutton P, Costanza R (2002) Global estimates of market and non-market values derived from nighttime satellite imagery, land cover, and ecosystem service valuation. Ecol Econ. 41, 509-27.

Twieg BD, Durall DM, Simard SW (2007) Ectomycorrhizal fungal succession in mixed temperate forests. New Phytol 176(2):437-447. https://doi.org/10.1111/ j.1469-8137.2007.02173.x

Tyrväinen L, Pauleit S, Seeland K, De Vries S (2005) Benefits and uses of urban forests and trees. In Urban Forests and Trees: A Reference Book (pp. 81-114). https://doi.org/10.1007/3-540-27684-X_5.

Vancouver Board of Parks and Recreation (2016) Vancouver Biodiversity Strategy. Vancouver Canada. https://vancouver.ca/files/cov/biodiversity-strategy.pdf

Weng Q (2014) Global Urban Monitoring and Assessment through Earth Observation. CRC Press.

Westphal LM (2003) Social Aspects of Urban Forestry: Urban Greening and Social Benefits: a Study of Empowerment Outcomes. J Arboric 29(3):137-147.

Wiliams DAR, Matasci G, Coops NC (2018) High-resolution urban landcover mapping using RapidEye and LiDAR. ISPRS Photogrammetry and Remote Sensing (in review)

Zhang C, Pan Z, Dong H, He F, Hu X (2015). Remote Estimation of Leaf Water Content Using Spectral Index Derived From Hyperspectral Data, in: First International Conference on Information Science and Electronic Technology (ISET 2015). Atlantis Press.

Zarnoch SJ, Bechtold WA, Stolte KW (2004) Using crown condition variables as indicators of forest health. Can J For Res 34(5):1057-1070. https://doi.org/10. 1139/X03-277

\section{Submit your manuscript to a SpringerOpen ${ }^{\circ}$ journal and benefit from:}

- Convenient online submission

- Rigorous peer review

- Open access: articles freely available online

- High visibility within the field

- Retaining the copyright to your article

Submit your next manuscript at springeropen.com 